\title{
GROUND-MOTION PREDICTION EQUATIONS BASED ON DATA FROM THE HIMALAYAN AND ZAGROS REGIONS
}

\author{
MUKAT LAL SHARMA \\ Department of Earthquake Engineering, \\ Indian Institute of Technology Roorkee, \\ Roorkee 247667, India_mukutfeq@iitr.ernet.in \\ JOHN DOUGLAS \\ $B R G M-A R N / R I S$, \\ 3 avenue C. Guillemin, BP 36009 , \\ 45060 ORLEANS Cedex 2, France, j.douglas@brgm.fr \\ HILMAR BUNGUM \\ NORSAR / International Centre for Geohazards (ICG), \\ P.O. Box 53, Instituttveien 25, 2027 Kjeller, Norway, hilmar.bungum@norsar.no \\ JAINISH KOTADIA \\ Department of Earthquake Engineering, \\ Indian Institute of Technology Roorkee, \\ Roorkee 247667, India, jainishk@gmail.com \\ Received (received date)
Revised (revised date)
Accepted (accepted date) \\ This study derives ground-motion prediction equations for the horizontal elastic response spectral \\ acceleration for 5\% damping for application to the Indian Himalayas. The present equations include \\ a consideration of site category (rock/soil) and style-of-faulting (strike-slip/reverse). Due to a lack of \\ near-field data from India additional strong-motion data have been included from the Zagros region \\ of Iran, which has comparable seismotectonics to the Himalayas (continental compression). A set of \\ 201 records from 16 earthquakes were used within the regression. The derived model predicts \\ similar ground motions to previously published equations for the Himalayan region but with lower
} standard deviations.

Keywords: ground-motion prediction equations; strong-motion data; India; Iran; Himalayas

\section{Introduction}

One of the prerequisites for seismic hazard analyses is a ground-motion prediction equation (GMPE) to transform event parameters (e.g. earthquake location and magnitude) to site parameters characterising the seismic hazard at a site (e.g. peak ground acceleration, PGA). Douglas [2003] provides a recent review of GMPEs for PGA and elastic response spectral ordinates. When conducting a seismic hazard analysis it is 
important to select a set of GMPEs that are appropriate for the region of interest, i.e. they correctly predict the median ground motion and its variability.

For the Indian Himalayas due to limited strong-motion data there are only a few and relatively poorly constrained GMPEs available [e.g. Singh et al., 1996; Sharma, 1998; Sharma, 2000; Jain et al., 2000; Saini et al, 2002; Sharma and Bungum, 2006; Raghukanth and Iyanger, 2007], only two of which [Singh et al., 1996; Sharma, 1998] could pass the GMPE selection criteria of Cotton et al. [2006] (since the others were not published in international peer-reviewed journals). However, the Himalayas are an area of high seismic hazard, vulnerability and exposure, including many important civil engineering projects such as hydroelectric dams. Therefore, there is a great need for robust GMPEs in order to derive earthquake design parameters and for accurate earthquake hazard and risk assessments.

The main reason why sufficiently reliable GMPEs have so far not been derived for the Himalayan region is a lack of data, especially near-field data. This situation is in turn complicated by the fact that the tectonics of this region are very complex, including a great range of focal depths and significant differences between the western and eastern parts of the range. We have, therefore, found it necessary to complement the Himalayan data with data from comparable regions, which admittedly are hard to define. However, a seismotectonic comparison between the Himalayan and Zagros (Iran) regions demonstrates some similarities since they both are continental collision zones. Therefore, we have assumed that this seismotectonic similarity carries over to the observed earthquake ground motions and hence we have combined the much more abundant strong-motion data available from the Zagros region with data from the Himalayas.

This article begins with a discussion of the seismotectonic similarities between the Himalayan and Zagros regions, next the available strong-motion data from these two regions are presented and finally a set of GMPEs for the prediction of horizontal (geometric mean) elastic response spectral acceleration for 5\% damping are derived and compared with some existing models.

\section{Seismotectonic setting}

This section briefly compares and contrasts the seismotectonics of the Himalayas and the Zagros so as to justify the combination of strong-motion datasets from these two regions.

\subsection{The Himalayan region}

The Himalayas were formed by the collision of the Indian and Eurasian continents along the convergent boundary wherein the buoyant crust of the Indian plate was detached from the underlying mantle and its subsequent deformation raised the mountain range. Since the collision initiated about $50 \mathrm{Ma}$ ago India has been underthrusting Asia (Tibet) at a rate of $45-50 \mathrm{~mm} / \mathrm{yr}$ [Besse et al., 1988; see also Rowley and Currier, 2006; Aitchison et al., 2007]. GPS measurements indicate that India is moving northeast at a convergence rate of about $55 \mathrm{~mm} / \mathrm{yr}$, of which $18-22 \mathrm{~mm} / \mathrm{yr}$ is accounted for by the Himalayas [Bilham et al., 1997], and the remaining convergence is taken up farther north in Tibet 
and Asia [Avouac and Tapponier, 1993; Peltzer and Saucier, 1996]. The on-going northward convergence of India produces active deformation in the Himalaya, Tibet and adjoining areas, keeping the entire region seismically active.

The Himalayas occupy the northern part of the Indian subcontinent forming a roughly $400 \mathrm{~km}$ wide arcuate bend that is convex to the SSW and runs unbroken for about $2400 \mathrm{~km}$ between the mountain peaks of Nanga Parbat in the west and Namcha Barwa in the east, both of which are located where the trend of the mountains changes abruptly. The Himalayas are bounded by the Indo-Gangetic plains towards the south and the TransHimalaya ranges towards the north. The actual northern boundary may be taken as a more or less continuous depression running parallel to the Himalaya trend and containing the valleys containing the upper reaches of the Indus and the Tsangpo (named Bhramputra further downstream in Assam). Within the Himalayas, the mountain ranges are arranged in various linear belts: the Trans-Himalaya belt; the Main Central Crystalline belt, which is also called the Great or Higher Himalaya and comprises of high mountain peaks, 30 of which, including Mount Everest, have elevations in excess of $7300 \mathrm{~m}$; the Lesser Himalaya which comprises mostly of the mountains with elevations up to $4500 \mathrm{~m}$; and the southernmost outer Tertiary Foot Hill belt with elevations up to $1300 \mathrm{~m}$. The boundaries between the various belts are marked by thrusts. The Great and the Lesser Himalaya are also dissected by transverse deep valleys carrying drainage.

\subsection{The Zagros region}

The northward motion of Arabia relative to Asia makes the role of Zagros region for the Arabic-Central Iran collision tectonically somewhat similar to that of the Indian Himalayan Region for Indian-Eurasian plate collision. Recent results, largely from GPS studies, suggest that shortening across the central Zagros is roughly N-S at a rate of 10-12 mm per year [Tatar 2001; Hessami 2002]. Similarly, the Indian plate motion relative to Eurasian plate is northward. Both regions are compared by Talebian and Jackson [2004]. The Zagros mountain belt of Iran, which is part of the Alpine-Himalayan system, extends from the NW Iranian border to SW Iran, up to the Strait of Hormuz. This orogenic belt is the result of the collision between the continental Arabian plate and the so-called Iranian block belonging to Eurasia [Berberian and King, 1981]. In SW Iran the Zagros Mountains, being an important element in the active tectonics of south-west Asia, are one of the most seismically active intra-continental fold-and-thrust belts on Earth. Active faults and volcanic high surface elevations along the Himalayan-Alpide earthquake belt characterize the Iranian plateau.

With respect to the seismicity of Iran, most of the active tectonics is concentrated along the Zagros fold thrust belt in comparison to the central and eastern parts of Iran [Tavakoli and Ghafory-Ashtiany, 1999]. Surface faulting associated with earthquakes is rare and so most information about the active faulting comes from focal mechanisms derived by seismological analyses. In the central Zagros, between these two structural regimes, deformation involves parallel strike-slip faults that rotate about vertical axes, allowing extension along the strike of the belt. The overall configuration is similar to that 
seen in other curved shortening belts, such as the Himalayas. The convergence is still active, in a roughly $\mathrm{N}-\mathrm{S}$ direction at a rate of approximately $25-30 \mathrm{~mm} / \mathrm{yr}$ at the eastern edge of the Arabian plate [Sella et al., 2002].
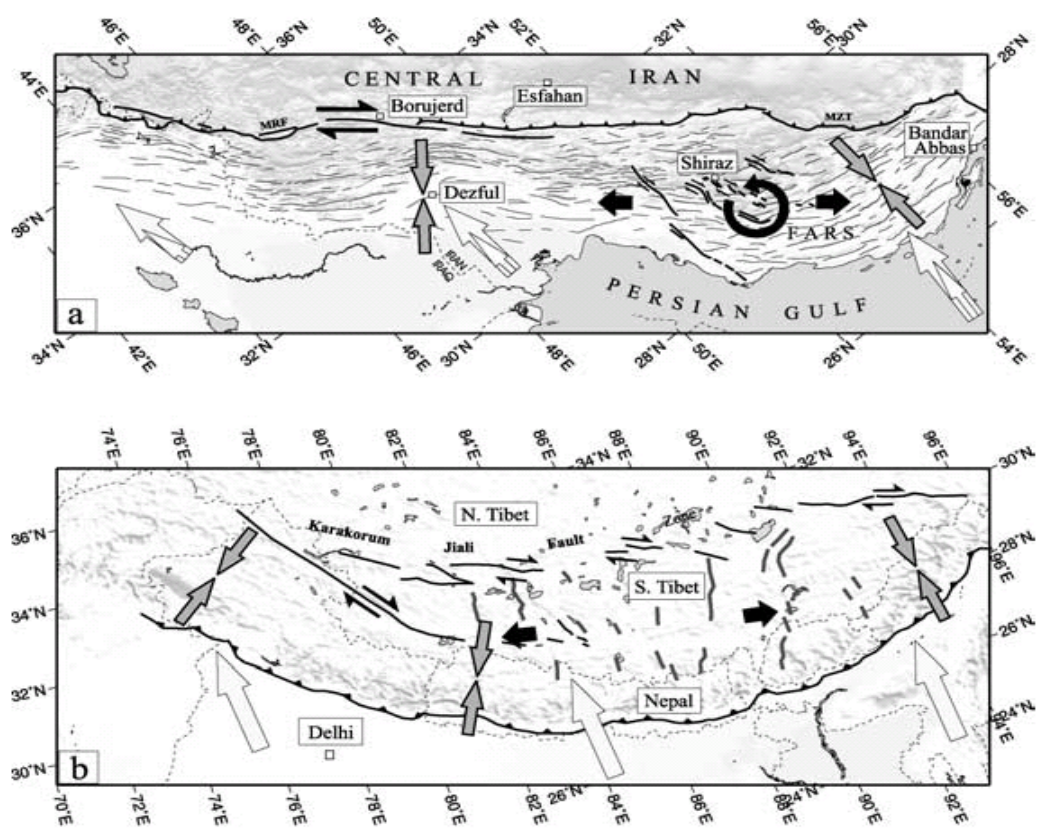

Figure 1. Comparison of Himalayas and Zagros region (After Talebian and Jackson, 2004).

\subsection{Comparison of the Himalayan and Zagros regions}

The Himalayan and the Zagros region have many similarities but they are dissimilar in other respects. In this section the similarities in the orogenic situation and the type of seismogenic sources present in the two regions are compared. The main objective of this comparison is to check that combining strong-motion records from the two regions to develop common GMPEs is justified. The two regions should have sufficiently similar orogeny and type of sources so that the collation results in homogenous data set for development of common GMPEs.

The comparison of Himalayas and Zagros region has been made by Talebian and Jackson [2004] as shown in Fig. 1. In the Zagros region, if a regional low-angle thrust surface exists it is evidently not seismically active and presumably creeps at depths beneath the seismogenic layer [Snyder and Barazangi, 1986]. In this respect the Zagros is clearly different from the Himalayas, where low-angle thrusting is seismically active throughout the region beneath the Lesser Himalaya to a depth of at least $15 \mathrm{~km}$ [e.g. Ni and Barazangi, 1986]. In the Himalayas, there is evidence in both the earthquake 
locations and the seismic anisotropy that the Indian shield underthrusts southern Tibet to a distance of at least $300 \mathrm{~km}$ beyond the Indus-Tsango suture (the northern limit of the Indian margin at the surface) and to a depth of $\sim 80 \mathrm{~km}$ [Huang et al. 2000; Jackson 2002]. By contrast, within the main part of the Zagros there is no such evidence from the earthquakes that the basement of Arabia underthrusts central Iran to any significant degree. Perhaps this is not surprising given that the amount of convergence since the suturing between India and southern Tibet $\sim 50 \mathrm{Ma}$ ago is much greater (perhaps $1000 \mathrm{~km}$ ) than that between Arabia and central Iran since they finally sutured 5-10 Ma ago (perhaps 50-100 km).

Furthermore, the Indian shield is known to be unusually strong, with an effective elastic thickness of $40 \mathrm{~km}$ [McKenzie and Fairhead, 1997; Jackson 2002], perhaps predisposing it to rigid underthrusting of Tibet, whereas the Arabian shield beneath the Persian Gulf has an effective elastic thickness of only $\sim 15 \mathrm{~km}$ and is significantly weaker [Maggi et al. 2000]. The only site where there is plausible seismic evidence for the underthrusting of the Arabian basement beneath the Zagros-central Iran suture is at the $\mathrm{SE}$ end of the belt, near the syntaxis of the Oman Line. In this region (near $57^{\circ} \mathrm{E}$ ) lowangle north-dipping thrusting earthquakes occur for about $50 \mathrm{~km}$ north of the suture, with centroid depths increasing northwards to a depth of nearly $30 \mathrm{~km}$.

The Zagros, therefore, shows some similarities with the Himalayas, such as the consequences of along-strike curvature of the belt, but also profound differences, such as the lack of earthquake evidence for low-angle underthrusting of the frontal part of range. It is remarkable how similar the kinematic scheme is for the Zagros compared to those in the Himalaya [McCaffrey and Nabelek, 1998]. Curvature of the belt causes a change from orthogonal to oblique convergence along strike, and the oblique shortening is achieved by partitioning. The resultant along-strike extension is achieved by strike-slip faulting in Zagros, and by normal faulting in southern Tibet.

\section{Strong-motion data used in this study}

This section discusses the strong-motion data from the two areas (Himalayas and Zagros) used for the regression analysis that follows. As noted above, the combination of data from these two areas is motivated by similarities in the tectonics of the two regions. We note, however, that the tectonics of the regions do show some differences, in particular in that the dip angles of reverse events in the Zagros are generally higher than for thrusting earthquakes in the Himalayas. Variations in the ground motions caused by these differences in focal mechanisms are, however, incorporated into the standard deviations of the derived model. Moreover, any differences in the predominant faulting type in the

Himalayas and the Zagros are approximately accounted for by the inclusion of a coefficient to model the effect of mechanism (strike-slip or reverse).

\subsection{Himalayan data}

The strong motion data available from the Indian Himalayas is limited. However, efforts have been made in the past to use this data to develop GMPEs [e.g. Singh et al., 1996; 
Sharma, 1998; Sharma, 2000; Sharma and Bungum 2006]. The Department of Earthquake Engineering, Indian Institute of Technology, Roorkee deployed three strongmotion arrays in the Indian Himalayas, namely: the Kangra array in Himachal Pradesh (NW India), Uttar Pradesh (UP) array (N India), and the Shillong array in Meghalaya and Assam (NE India). The Kangra array consists of 50 analogue strong-motion accelerographs (SMA-1); the Shillong array, 45; and the Uttar Pradesh array, 40. The Kangra array is located in the Lesser Himalayas with elevations ranging from 470 to $2700 \mathrm{~m}$. There are numerous faults and thrusts, but among these, two are of prominence and can be traced all along the length of the Himalayas (Figure 2).

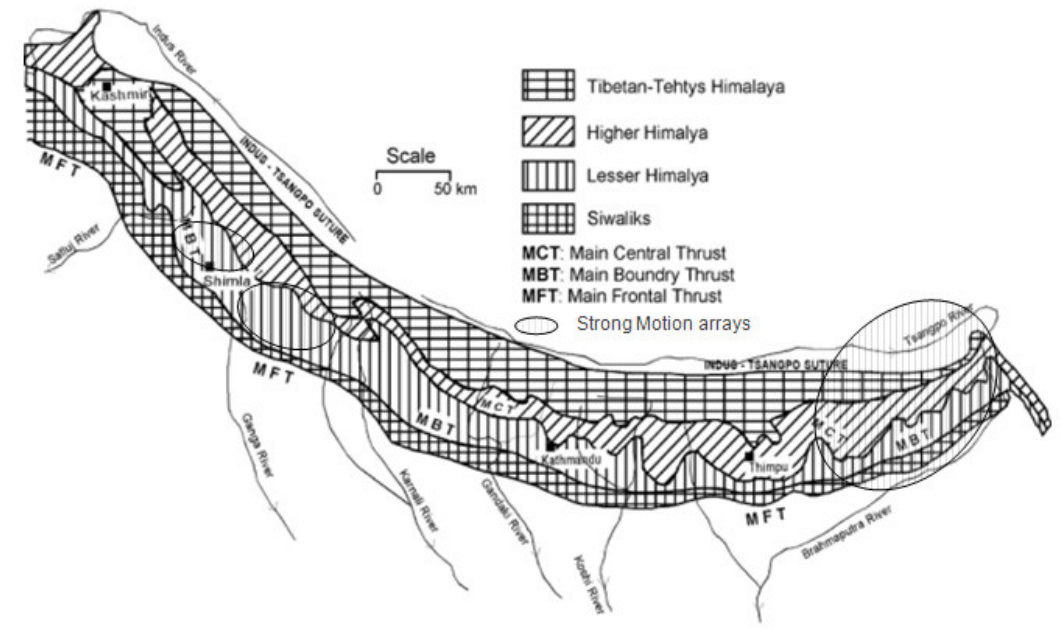

Fig 2. Seismotectonic features and the location of strong motion arrays in the Himalayas.

In the Himalayas, the Main Central Thrust (MCT) separates the largely crystalline Greater (Higher) Himalaya from the Lesser (Lower) Himalaya, mainly sedimentary and Precambrian metamorphic rocks, while the Main Boundary Thrust (MBT) separates the Lesser Himalaya from the Tertiary Shiwaliks towards the foothills. Since early Tertiary times the collision between the Indian subcontinent and Eurasia has shifted southwards, so that at present the main principal tectonic displacement takes place near the Main Frontal Thrust (MFT), which, however, is more vaguely defined than the MCT and the MBT. The foothills of the Himalaya have been repeatedly struck by large earthquakes, notably in 1897, 1905, 1934 and 1950 (e.g. Yeats et al., 1997).

The UP array is deployed around the MBT and MCT in the UP Himalayas. The array trends northwest to southeast covering a length of about $280 \mathrm{~km}$ and follows the regional strike of the tectonic features and merges with the Kangra array in the NW. The Shillong array is deployed in the Shillong massif in the states of Meghalaya and Assam. It mainly 
encompasses the most active features of the region, namely, the Dauki fault zone, the Dhubri fault, and the Haflong Disang thrust zone. Regionally, northeast India can be classified into four major tectonic units: the Arunachal Himalayas, the Lohit Himalayas, the Patkai-Naga-Luhasi-Arakan-Yoma (Indo-Burma) hill ranges and the Shillong plateau-Assam basin. In the Shillong massif and Mikir Hills the basement rocks are exposed and are surrounded by Tertiary formations. The wedge-shaped Shillong plateau is a horst that has been block uplifted since the Jurassic period.

The available strong-motion data comes from 11 earthquakes, recorded at various stations, covering a magnitude range between 4.9 and 6.8 and hypocentral distances up to $300 \mathrm{~km}$ [Sharma, 1998; Shrikhande, 2001]. The locations, focal mechanisms and magnitudes of the events selected from the Himalayan region are shown in Fig. 3. The data used in this study are listed in Table 1. The site classifications for the Indian stations were taken from Das and Chandrasekaran [1993].

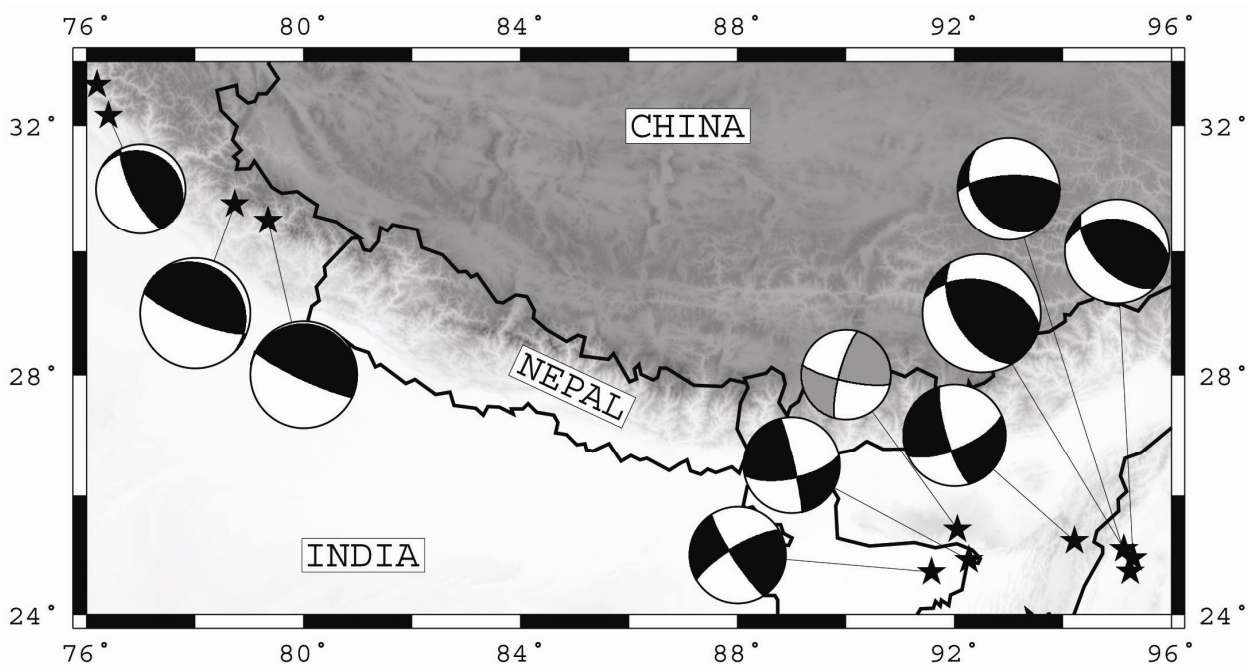

Fig. 3. Locations (stars) and focal mechanisms (beachballs) of the events from the Himalayan region selected. The size of each beachball is proportional to the magnitude of the earthquake. Focal mechanisms are taken from Global CMT except for the grey beachball, which is from S. Barush (personal communication). One earthquake (north-west corner of map) does not have an associated focal mechanism available.

In the present study moment magnitude $\left(\mathrm{M}_{\mathrm{W}}\right)$ has been used to define earthquake magnitude (for details, see Sharma and Bungum, 2006). The use of moment magnitude avoids the saturation of the more traditional band-limited magnitude measures for large events and, therefore, is considered to be a better measure of the true size of an earthquake. Some earlier studies used surface wave magnitude for earthquakes with surface-wave magnitude $M_{S}>6$ and local magnitude $\left(M_{L}\right)$ to define earthquake magnitude for the events with $\mathrm{M}_{\mathrm{S}}<6$. A comparison of magnitude scales presented by Heaton et al. [1986] indicates that $M_{S}$ and $M_{L}$ are approximately equal to $M_{W}$ for $\mathrm{M}_{\mathrm{L}}<6.5$ and that $\mathrm{M}_{\mathrm{S}}$ is approximately equal to $\mathrm{M}_{\mathrm{W}}$ for $\mathrm{M}_{\mathrm{S}}$ ranging from 6.0 to 8.0. 
Therefore, the magnitude measures used in these earlier studies are largely consistent with $\mathrm{M}_{\mathrm{W}}$ over the range of magnitudes of engineering interest.

Table 1. Data used for final regression, where NR is number of records used with the regression. The magnitude-distance distribution is shown in Figure 5. * indicates Iranian events not located in the Zagros.

\begin{tabular}{|c|c|c|c|c|c|c|c|}
\hline & $\begin{array}{l}\text { Event } \\
\text { code }\end{array}$ & Name of earthquake & $\begin{array}{c}\text { Date } \\
\text { dd-mm-yyyy }\end{array}$ & $\begin{array}{c}\text { Depth } \\
(\mathrm{km})\end{array}$ & $\mathrm{M}_{\mathrm{w}}$ & $\begin{array}{l}\text { Style of } \\
\text { faulting }\end{array}$ & NR \\
\hline \multirow{6}{*}{$\underset{\Xi}{\stackrel{\tilde{J}}{\Xi}}$} & \multirow{6}{*}{$\begin{array}{l}\text { Ind1 } \\
\text { Ind2 } \\
\text { Ind3 } \\
\text { Ind4 } \\
\text { Ind5 } \\
\text { Ind6 }\end{array}$} & Dharmsala & 26-04-1986 & 33 & 5.5 & Reverse & 5 \\
\hline & & North-East India & $10-09-1986$ & 43 & 5.5 & Strike-slip & 9 \\
\hline & & India-Burma border & $18-05-1987$ & 50 & 6.3 & Strike-slip & 13 \\
\hline & & Uttarkashi & 20-10-1991 & 19 & 6.8 & Reverse & 13 \\
\hline & & India-Burma border & 08-05-1997 & 35 & 5.9 & Strike-slip & 10 \\
\hline & & Chamoli & 28-03-1999 & 21 & 6.6 & Reverse & 8 \\
\hline \multirow{10}{*}{$\underset{\mathbb{I}}{\mathbb{E}}$} & \multirow{10}{*}{$\begin{array}{l}\text { Ira1 } \\
\text { Ira2 } \\
\text { Ira3 } \\
\text { Ira4 } \\
\text { Ira5 } \\
\text { Ira6 } \\
\text { Ira7 } \\
\text { Ira8 } \\
\text { Ira9 } \\
\text { Ira10 }\end{array}$} & Zanjiran & 20-06-1994 & 6 & 5.9 & Strike-slip & 6 \\
\hline & & Sarein(Ardebil)* & 28-02-1997 & 15 & 6.1 & Strike-slip & 5 \\
\hline & & Karebas & 06-05-1999 & 33 & 6.2 & Strike-slip & 13 \\
\hline & & Pol-e-Abgineh & 31-10-1999 & 33 & 5.2 & Reverse & 4 \\
\hline & & Avaj-Changeruh* & $22-06-2002$ & 5 & 6.5 & Reverse & 21 \\
\hline & & Bam* & $26-12-2003$ & 7 & 6.6 & Strike-slip & 12 \\
\hline & & Kojur - Firoozabad* & $28-05-2004$ & 25 & 6.3 & Reverse & 52 \\
\hline & & Dahooeiyeh-Zarand* & $22-02-2005$ & 10 & 6.4 & Reverse & 12 \\
\hline & & Qeshm Island & $27-11-2005$ & 10 & 6.0 & Reverse & 8 \\
\hline & & Silakhor & $31-03-2006$ & 12 & 6.1 & Strike-slip & 10 \\
\hline
\end{tabular}

\subsection{Zagros data}

The Zagros Mountains of SW Iran form a linear intra-continental fold-and-thrust belt trending NW-SE between the Arabian shield and central Iran. It is currently one of the most seismically active belts in Asia, with frequent earthquakes of magnitudes up to 7.0. Iranian data used in this study has been made available by the Iran Strong Motion Network (ISMN) on their website (http://www.bhrc.ac.ir/ISMN/Index.htm). The 12 selected earthquakes cover a magnitude range between 5.2 and 6.9 and hypocentral distances up to $400 \mathrm{~km}$ (see Table 1). Iranian stations were classified using site information from Zaré et al. [1999a], Shoja-Taheri et al. [2005], Jackson et al. [2006] and Zafarani et al. [2008]. The focal mechanisms of the events selected from the Iranian data are shown in Fig. 4. This figure (and Table 1) shows that five of the Iranian events selected occurred to the east of the Zagros belt. These events were included due to their similar focal mechanisms to the Zagros earthquakes and since we did not notice a significant difference in ground motions between these events and those in the Zagros region (similarly Ghasemi et al. [2009] did not find a significant difference in ground motions in Zagros and non-Zagros events).

Comparing Figures 3 and 4 shows that focal mechanisms of selected earthquakes from the Himalayas and Iran are similar (strike-slip and steep reverse-faulting) except for three shallow-dip thrust-faulting events in the north-west region of the Himalayas; a type of mechanism that does not occur in Iran. This similarity in mechanisms in the two 
regions adds weight to our assumption of comparable ground motions in the Himalayas and the Zagros.

Various GMPEs for Iran have been published [e.g. Ramazi and Schenk, 1994; Zare et al., 1999b; Khademi, 2002; Ghasemi et al., 2009] although few of these are for response spectral ordinates and few would pass the selection criteria of Cotton et al. [2006]. In addition, a number of GMPEs for use in Europe and the Middle East have used data from Iran [e.g. Chiaruttini and Siro, 1981; Ambraseys and Bommer, 1991; Ambraseys et al., 1996; Berge-Thierry et al., 2003; Ambraseys et al., 2005].

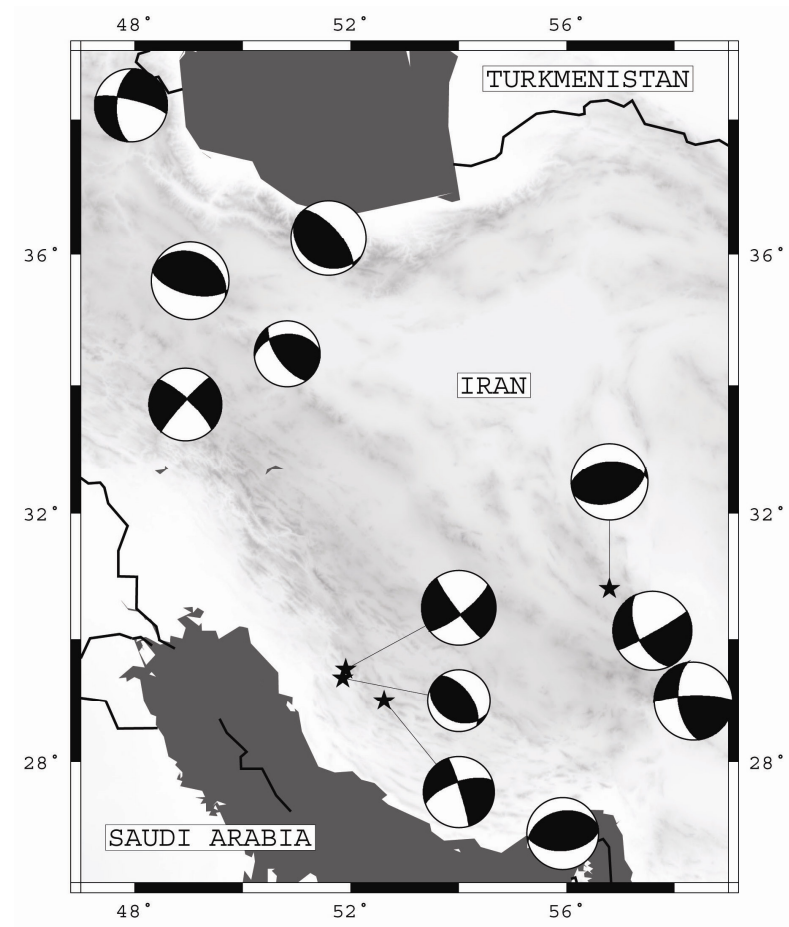

Fig. 4. Locations (stars) and focal mechanisms (beachballs) of the Iranian events selected. The size of each beachball is proportional to the magnitude of the earthquake. Focal mechanisms are taken from Global CMT.

\subsection{Magnitude-distance distributions}

Figure 5 shows the distribution of available records in terms of moment magnitude, $\mathrm{M}_{\mathrm{W}}$, and distance to the surface projection of the rupture (Joyner-Boore distance, $\mathrm{R}_{\mathrm{JB}}$ ) for the combined Himalaya-Zagros dataset. This figure reveals that there is insufficient data for development of robust GMPEs using only data from the Himalayan region but that the addition of records from the Zagros region, which as discussed above is 
seismotectonically similar to the Himalayas, fills most of the gaps in the distribution between magnitudes 6 and 7. Overall, the combine dataset seems to be adequate for the development of GMPEs for the prediction of ground motions between magnitudes 5 and 7 for distances less than $100 \mathrm{~km}$. Outside this magnitude-distance range the limited data available (even when combining records from the two regions) means reliable fully empirical ground-motion models cannot be developed. We note that there is currently more strong-motion data available (and selected) from Iran than from India (58 records from India and 143 from Iran) and, therefore, it could be argued that the model developed here is more applicable for Iran than for India. However, we believe that the use of data from India means that the model developed here is more applicable to the Himalayas than simply adopting a GMPE from another region (a common practice). Another observation from Figure 5 is that most of the data from Iran is concentrated between magnitudes 5.9 and 6.6 whereas the data from India are mostly from smaller and larger magnitudes. This means that it is difficult to statistically check that the ground motions from the two regions are comparable.

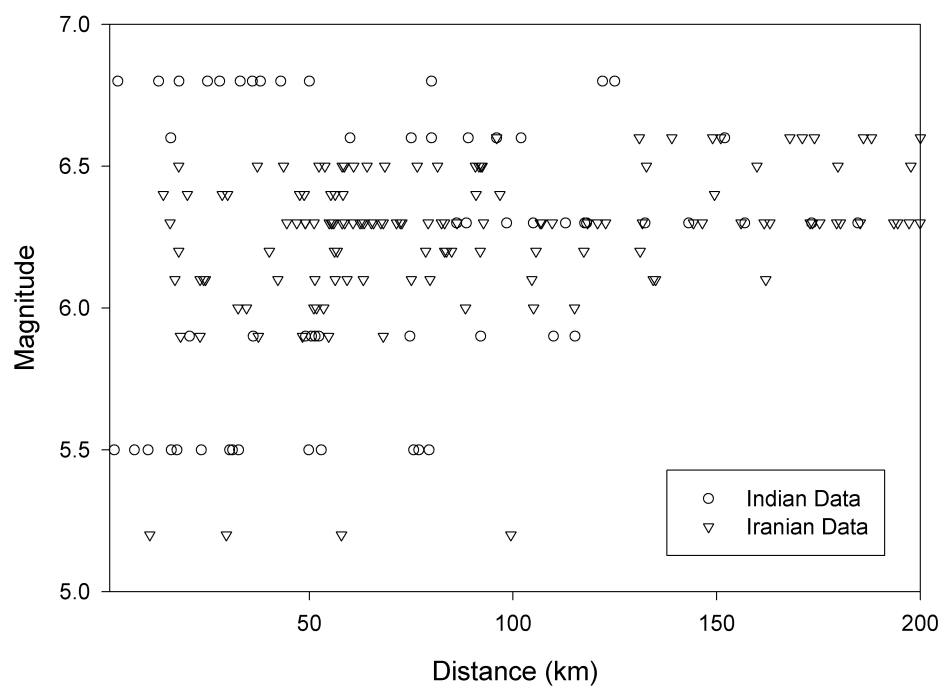

Fig. 5. Moment magnitude-Joyner-Boore distance distribution of strong-motion data from the Himalayas and the Zagros regions.

\section{Data set used to develop the GMPEs}

A prerequisite for developing robust GMPEs is a reasonably homogeneous dataset. Past attempts at developing GMPEs for India have to this end revealed problems with the available dataset. The lack of data is partly due to analogue records from three Himalayan earthquakes (the Bangladesh-India border earthquake of 31 December 1984, the Bihar Earthquake of 21 August 1988 and the Delhi Earthquake of 28 July 1994) not yet having been digitised. 
In order to exclude data from earthquakes whose ground motions show anomalous behaviour the PGAs from each earthquake were plotted individually against distance. It was found that for the decay rate of PGA for the India-Bangladesh border earthquake of 6 February 1988, and for the Golbaf earthquake of 14 March 1998, are different than from other events. Therefore, data from these two events were excluded so as not to affect the GMPEs by data that may not be typical of ground motions in the Himalaya and Zagros regions.

In addition, due to their great hypocentral depths (more than $90 \mathrm{~km}$ ) the India-Burma border events of 6 August 1988, 10 January 1990 and 6 May 1995 were excluded from further consideration since the purpose of this article is the development of GMPEs for shallow crustal earthquakes. Ground motions from deep events have significantly different characteristics (e.g. in terms of scaling with distance) than those with shallow foci.

For this study, the distance to the surface projection of the rupture (Joyner-Boore distance), $\mathrm{R}_{\mathrm{JB}}$, has been chosen as the distance metric. This choice was partly motivated by the lack of reliable depths for most of the Himalayan earthquakes and hence the $R_{J B} S$ should be more accurate than distances to the rupture, $\mathrm{R}_{\mathrm{rup}}$, which require accurate depths for their calculation. Due to the lack of $\mathrm{R}_{\mathrm{JB}} \mathrm{S}$ in the literature for most of the Indian and Iranian strong-motion records used, we estimated these distances using reported locations of the fault rupture for the Himalayan earthquakes of: Uttarkashi 1991(Ind4) and Chamoli 1999 (Ind6) and for the Zagros events of: Avaj-Changeruh 2002 (Ira5), Bam 2003 (Ira6), Kojur - Firoozabad 2004 (Ira7), Dahooeiyeh-Zarand 2005(Ira8) and Qeshm Island 2005 (Ira9). For the other events the location of the fault plane was estimated by using the reported focal mechanism and the relationships of Wells and Coppersmith [1994] to estimate the length and width of the subsurface rupture (the hypocenter was assumed to be in the centre of the rupture plane). Since focal mechanisms for the earthquakes of: the India-Burma border on 9 January 1990, Chamba on 24 March 1995, Chamoli on 14 December 2005, Alwar on 29 November 2006, Mandi on 10 December 2006, Roorkee on 9 June 2007, Noida on 18 October 2007 and Bahadurgarh on 25 November 2007 could not be found records from these events were rejected. This limited the number of usable earthquakes from India to only six (three strike-slip and three reverse) and from Iran to only ten (five strike-slip and five reverse). In total 201 records, 132 from soil sites and 69 from rock sites, were retained for regression analysis ( 58 from India and 143 from Iran).

For each of the 201 records from the 16 earthquakes the geometric means of the two horizontal components of elastic response spectral acceleration for a damping of $5 \%$ were computed for 67 periods between 0.04 and 2.5s. In this article, only the coefficients for a subset of these periods are reported

\section{Development of ground-motion relationships}

The functional form selected for the GMPEs is:

$$
\log A=b_{1}+b_{2} M_{w}-b_{3} \log \sqrt{R_{J B}^{2}+b_{4}^{2}}+b_{5} S+b_{6} H
$$


where $b_{1}, b_{2}, b_{3}, b_{4}, b_{5}$ and $b_{6}$ are the regression coefficients, $A$ is spectral acceleration in terms of $\mathrm{m} / \mathrm{sec}^{2}$ and $\mathrm{S}$ is 1 for a rock site and 0 otherwise and $\mathrm{H}$ is 1 for a strike-slip mechanism and 0 for a reverse mechanism.

In an ideal data set, there would be a uniform sampling of spectral acceleration over all magnitudes and distances. Due to limited data weighting regression analysis is sometimes performed to limit the effect of a non-uniform distribution (Sharma, 1998; Abrahamson and Litehiser, 1989). The data set exhibits a high correlation between distance and magnitude, which is commonly observed in strong-motion datasets. To limit the effect of this correlation we followed the explicit weighting method of Campbell (1981). The weights are determined by dividing the data into a number of subsets based on distance. In each distance interval each earthquake is given equal weight by assigning a relative weight of $1 / n_{j 1}$ to the record where $n_{j 1}$ is the total number of recordings for the $\mathrm{j}$ th earthquake within the ith distance bin. In this study we have given more importance to records from short distances than distant records because of the lack of near-source data (see Figure 5). For this purpose the complete distance range is divided into three parts on a logarithmic scale. Equal weights were given to the recordings falling in ranges up to $10 \mathrm{~km}, 10$ to $100 \mathrm{~km}$ and more than $100 \mathrm{~km}$ with the farthest at $232 \mathrm{~km}$. The weights were normalised to unity in each distance bin and then the weights were normalised to unity by using the complete dataset. These weights were used within the regression.

The final coefficients calculated for the GMPEs are given in Table 2 for selected spectral periods. After trials with different values $b_{4}$ was fixed to be $15 \mathrm{~km}$ for all periods. The spectral acceleration for $0.04 \mathrm{sec}$ period is shown in Figure 6 for magnitudes 5, 6 and 7 for various combinations of soil/rock and reverse/strike slip conditions. The whole spectra is plotted for the magnitude 5, 6, and 7 for the two conditions (i) rock and strike slip and (ii) soil and reverse at a distances of $10 \mathrm{~km}, 50 \mathrm{~km}$ and $100 \mathrm{~km}$.

Table 2. Coefficients for the developed GMPEs for spectral acceleration

\begin{tabular}{|c|c|c|c|c|c|c|c|c|c|c|c|}
\hline $\mathrm{T}$ & $\mathrm{b} 1$ & std err & $\mathrm{b} 2$ & std err & $\mathrm{b} 3$ & std err & b5 & std err & b6 & std err & Std dev \\
\hline 0.04 & 1.0170 & 0.3164 & 0.1046 & 0.0419 & -1.0070 & 0.1368 & -0.0735 & 0.0431 & -0.3068 & 0.0409 & 0.3227 \\
\hline 0.05 & 1.0280 & 0.3178 & 0.1245 & 0.0421 & -1.0550 & 0.1374 & -0.0775 & 0.0433 & -0.3246 & 0.0411 & 0.3350 \\
\hline 0.10 & 1.3820 & 0.3165 & 0.1041 & 0.0419 & -1.0620 & 0.1368 & -0.1358 & 0.0432 & -0.3326 & 0.0409 & 0.3427 \\
\hline 0.20 & 1.3820 & 0.3165 & 0.1041 & 0.0419 & -1.0620 & 0.1368 & -0.1358 & 0.0432 & -0.3326 & 0.0409 & 0.3596 \\
\hline 0.30 & 1.3680 & 0.3977 & 0.0684 & 0.0527 & -0.9139 & 0.1720 & -0.0972 & 0.0542 & -0.3011 & 0.0514 & 0.3651 \\
\hline 0.40 & 0.9747 & 0.3675 & 0.1009 & 0.0487 & -0.8886 & 0.1589 & -0.0552 & 0.0501 & -0.2639 & 0.0475 & 0.3613 \\
\hline 0.50 & 0.5295 & 0.3876 & 0.1513 & 0.0514 & -0.8601 & 0.1676 & -0.0693 & 0.0529 & -0.2533 & 0.0501 & 0.3654 \\
\hline 0.75 & -0.5790 & 0.4079 & 0.3147 & 0.0541 & -0.9064 & 0.1764 & -0.0111 & 0.0556 & -0.2394 & 0.0527 & 0.3770 \\
\hline 1.00 & -1.6120 & 0.3922 & 0.4673 & 0.0520 & -0.9278 & 0.1696 & -0.0203 & 0.0535 & -0.2355 & 0.0507 & 0.3949 \\
\hline 1.25 & -1.7160 & 0.4250 & 0.4763 & 0.0563 & -0.9482 & 0.1838 & -0.0200 & 0.0580 & -0.2921 & 0.0549 & 0.4190 \\
\hline 1.50 & -2.1380 & 0.4284 & 0.5222 & 0.0568 & -0.9333 & 0.1852 & 0.0284 & 0.0584 & -0.3197 & 0.0554 & 0.4251 \\
\hline 2.00 & -2.6900 & 0.4084 & 0.5707 & 0.0541 & -0.9082 & 0.1766 & 0.0400 & 0.0557 & -0.2770 & 0.0528 & 0.4077 \\
\hline 2.50 & -2.9420 & 0.3944 & 0.5671 & 0.0523 & -0.8270 & 0.1706 & 0.0054 & 0.0538 & -0.2710 & 0.0510 & 0.3959 \\
\hline
\end{tabular}




\section{Results}

Predicted ground motions with respect to distance from the developed GMPEs are presented on Figure 6 for magnitudes 5, 6 and 7 for various site classifications and faulting mechanism for a spectral period of $0.04 \mathrm{~s}$. Figures 7 to 9 compare predict response spectra for various source-to-site distances, site classifications and mechanisms. The model derived here has a strong dependence on faulting mechanism: predicted spectral accelerations from reverse events are roughly twice those from strike-slip earthquakes for all periods, which is greater than the 10-30\% usually found (e.g. Ambraseys et al, 2005). The dependence of spectral accelerations on site classification is weak especially at long periods, which is surprising and could be due to poor site characterisation. One prominent feature is a wide plateau until 1s in the predicted spectra, which, if not due to a deficiency of the dataset, would mean significantly larger predicted long-period spectral ordinates for the Himalayas and the Zagros than are estimated using GMPEs derived for other regions.

Sharma and Bungum (2006) derived GMPEs for spectral acceleration based on a combined dataset from the Himalayas and Europe (using reverse events) and a similar functional form and regression methodology. Figure 10 compares the predictions given by their GMPEs and those developed in this article for reverse faulting, since only reverse faulting was considered in the dataset of Sharma and Bungum (2006). This comparison shows that the newly derived GMPEs predict much lower intermediateperiod (0.5-1s) accelerations for rock sites but similar estimated ground motions at all periods for soil sites. The main problem with the model of Sharma and Bungum (2006), however, was that the predicted levels for magnitudes around 5, which influence hazard levels at low return periods (100-500 years), were quite high, in part reflecting problems with the magnitude-distance distribution.

Figures 11 to 13 compare predicted PGAs (assumed equal to the spectral acceleration at $0.04 \mathrm{~s}$ for the GMPEs derived here) with those estimated by three recent GMPEs using $\mathrm{M}_{\mathrm{w}}$ and $\mathrm{R}_{\mathrm{JB}}$ : Ambraseys et al (2005), Akkar and Bommer (2007) and Boore and Atkinson (2008). These comparisons show that the GMPEs derived here predict similar PGAs for reverse events as the other three models but that the predictions for strike-slip motions are much lower. In addition, our GMPEs predict less rapid decay for small events than the other models, probably because we assumed a magnitude-independent decay in contrast to the authors of the other models.

The standard deviations of the derived GMPEs (0.32-0.43) are higher than those of ground-motion models derived for other regions, especially at long periods. This is partly due to the low quality of the site characterisation for stations used here and since estimated source-to-site distances for Indian events are associated with large uncertainties. In addition, the simple functional form adopted means that the complex ground-motion generation and propagation in the Himalayas and the Zagros cannot be well modelled. These large standard deviations will have a significant impact on assessed ground motions from probabilistic seismic hazard analysis especially at long return periods and therefore it is recommended that efforts are taken to reduce the uncertainty in 
the associated parameters (particularly source-to-site distances and site classifications) for these data.

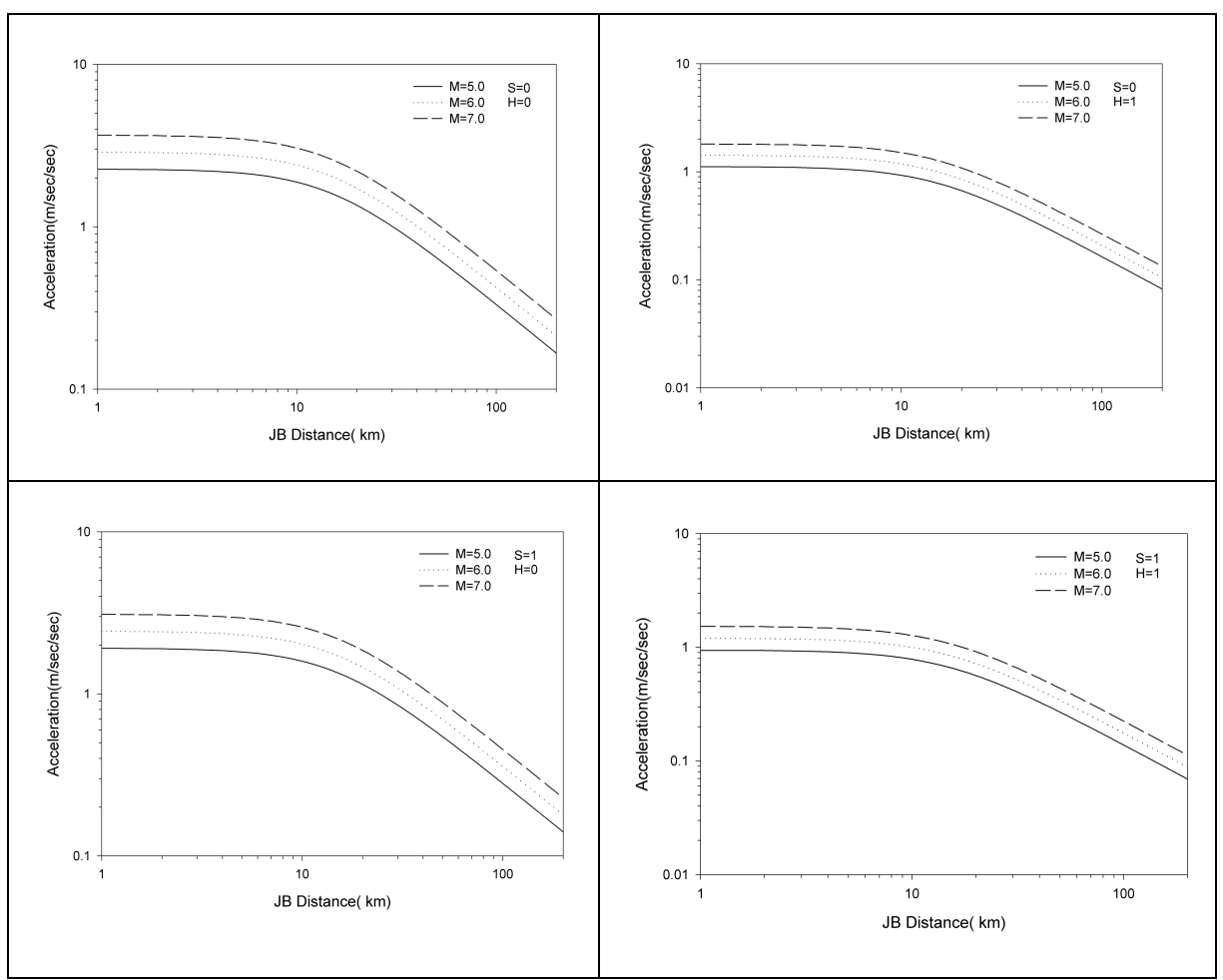

Figs. 6. Spectral Acceleration with respect to JB distance for magnitude 5, 6, and 7 for different combinations of soil/rock and reverse/strike slip cases. 


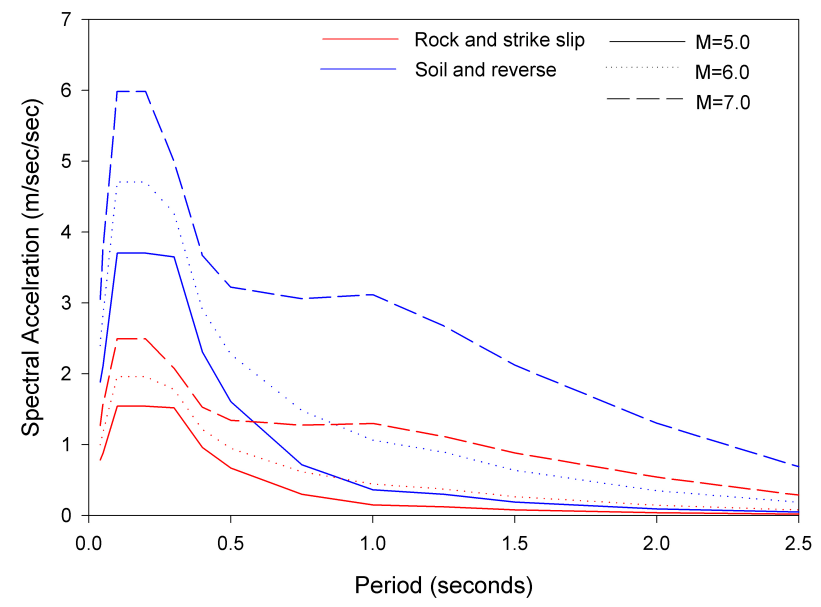

Fig. 7. Spectral accelerations for magnitude 5, 6 and 7 for two cases: (i) Rock and strike slip and (ii) Soil and reverse, both at a distance of $10 \mathrm{~km}$.

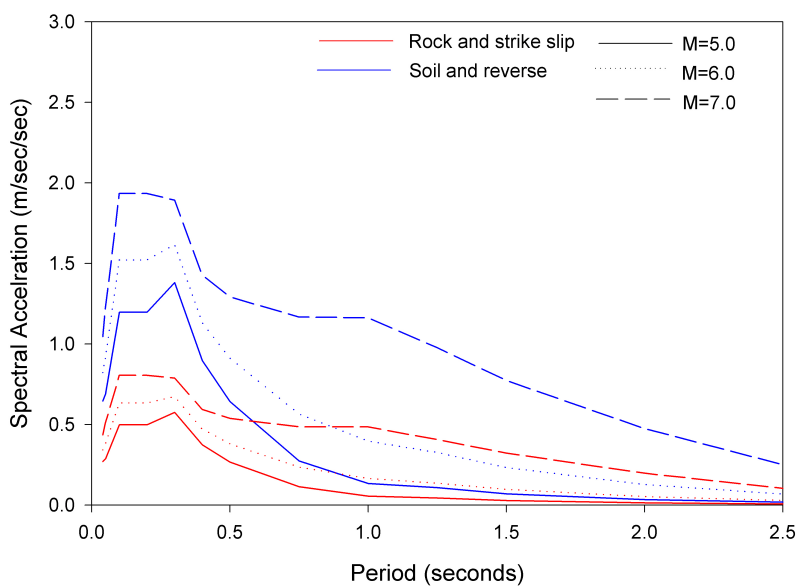

Fig. 8. Spectral accelerations for magnitude 5, 6 and 7 for two cases: (i) Rock and strike slip and (ii) Soil and reverse, both at a distance of $50 \mathrm{~km}$. 


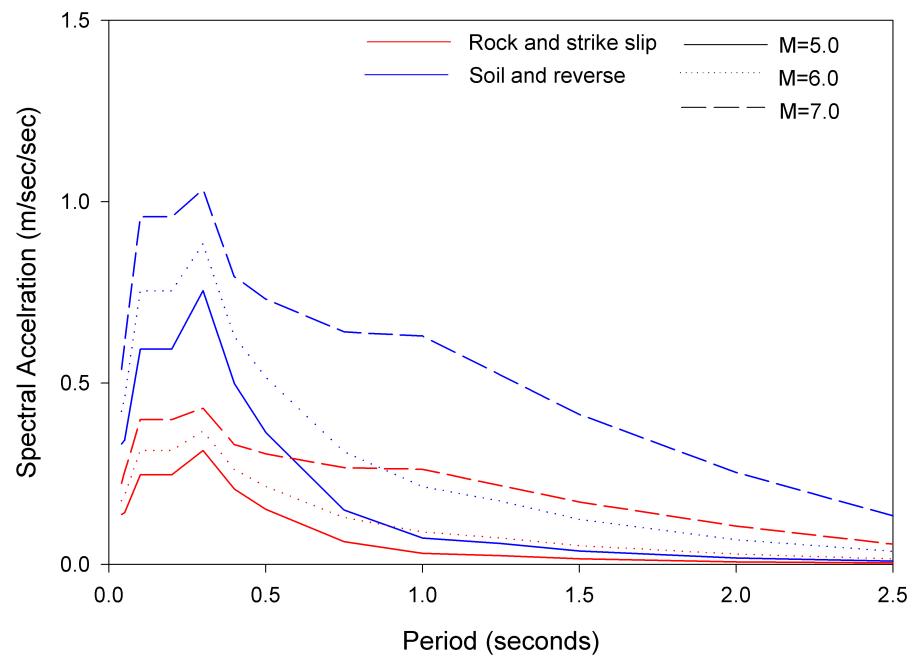

Fig. 9. Spectral accelerations for magnitude 5, 6 and 7 for two cases namely (i) rock and strike slip and (ii) Soil and reverse at a distance of $100 \mathrm{~km}$.

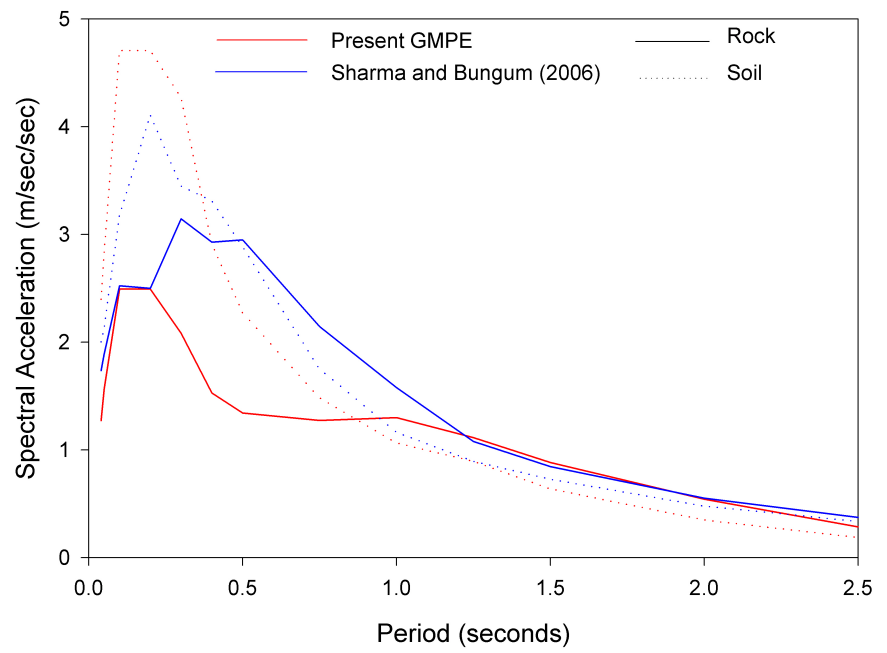

Fig. 10. Comparison of the predictions for $\mathrm{M}_{\mathrm{W}} 6$ and $\mathrm{R}_{\mathrm{JB}}=10 \mathrm{~km}$ from the GMPEs derived here and those presented by Sharma \& Bungum (2006) based on a combined Himalayan-European dataset. 


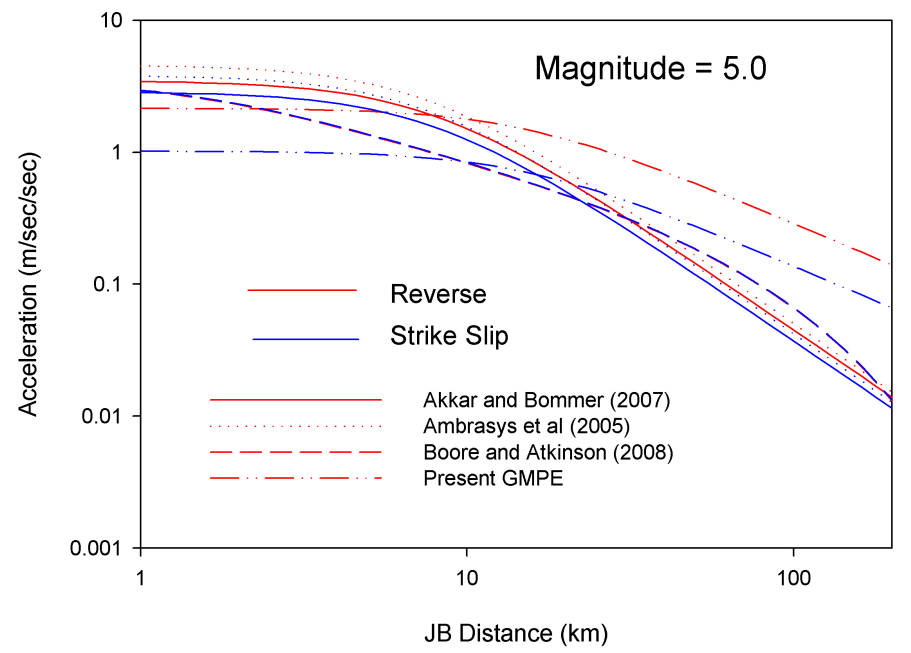

Fig. 11. Comparisons between the present ground-motion prediction results and those from Ambraseys et al. [2005], Akkar and Bommer [2007], and Boore and Atkinson [2008], for different modes of faulting and a moment magnitude of 5.0.

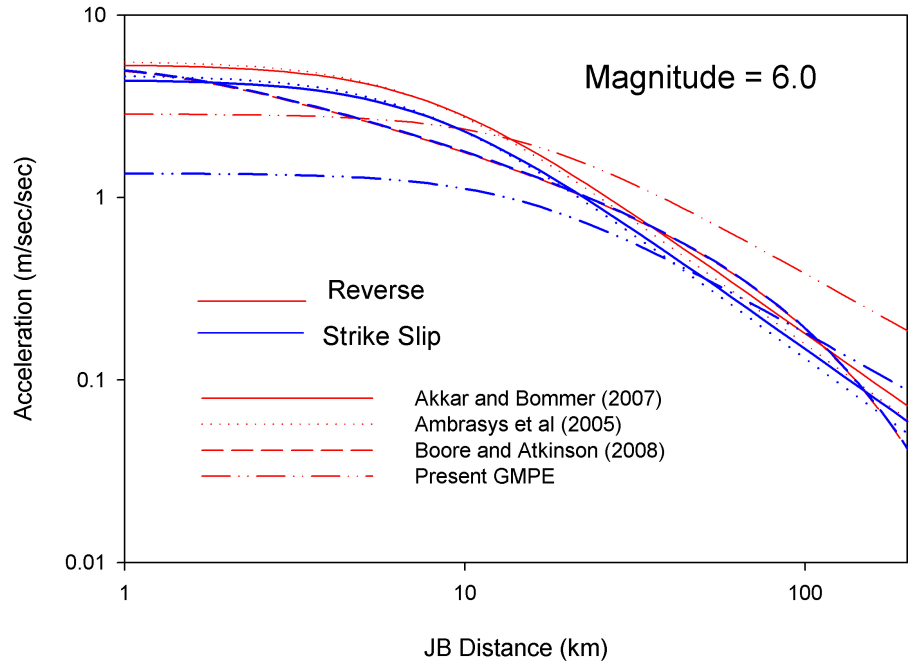

Fig. 12. Comparisons between the present ground-motion prediction results and those from Ambraseys et al. [2005], Akkar and Bommer [2007], and Boore and Atkinson [2008], for different modes of faulting and a moment magnitude of 6.0 . 


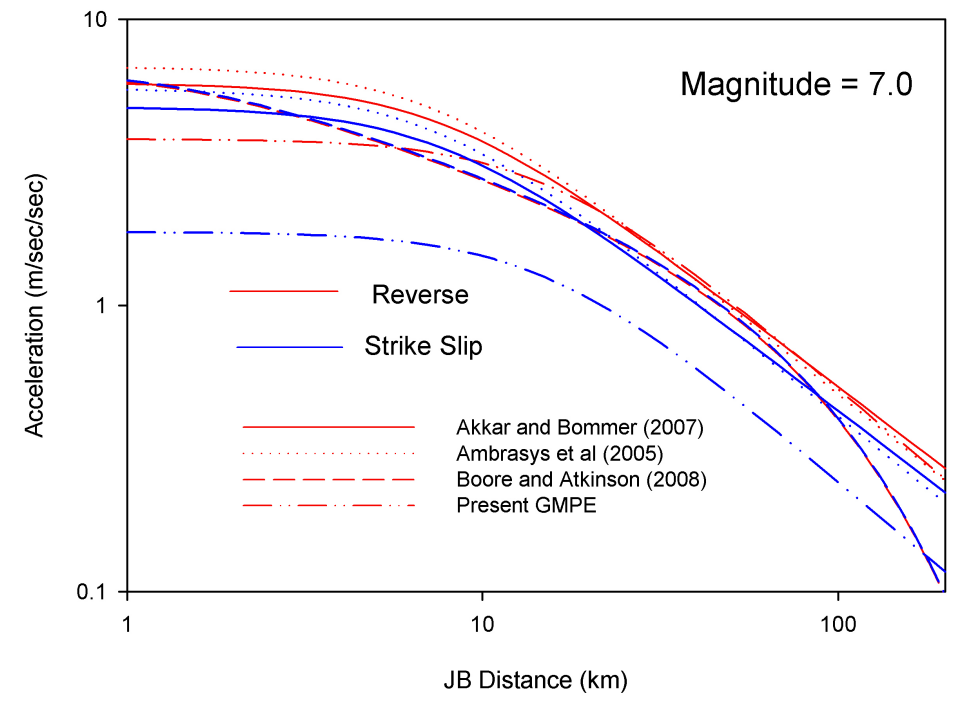

Fig. 13. Comparisons between the present ground-motion prediction results and those from Ambraseys et al. [2005], Akkar and Bommer [2007], and Boore and Atkinson [2008], for different modes of faulting and a moment magnitude of 7.0.

\section{Conclusions}

In this article, empirical GMPEs for the estimation of elastic response spectral accelerations have been derived for use in seismic hazard assessments for the Himalayas. Due to the lack of sufficient strong-motion data from the sparse and relatively recent accelerographic networks in the Indian Himalayas we have combined the small available dataset from this region with a larger dataset from the Zagros region. The Zagros has been identified in previous studies as a region with seismotectonic similarities to the Himalayas and, therefore, we have assumed that these similarities stretch over into the ground-motion domain and that the two strong-motion datasets can be combined.

The derived GMPEs predict a strong dependence on faulting mechanism (reverse motions are significantly greater than those from strike-slip events) but a weak dependence on site classification. Predictions from the derived model are, in general, similar to those given by previous GMPEs for shallow crustal earthquakes in other regions although the newly derived models predict lower strike-slip motions and greater motions at long distances. In addition, the shape of the predicted response spectra shows more long-period energy than is commonly predicted for shallow crustal earthquakes. However, the relatively low quality of the metadata available for Indian and Iranian strong-motion data means that the standard deviations of the presented GMPEs are high.

In conclusion, the GMPEs derived in this study could be considered within a logictree formulation for seismic hazard assessments in the Himalayan region, an area of 
growing seismic risk due to rapid urbanization. However, efforts should be made to improve the quality of the associated parameters (particularly the site characterization) and the amount of data available, for example through the digitization of existing analogue accelerograms.

\section{Acknowledgments}

The initial part of this work was supported by the Indo-Norwegian Programme on Institutional Cooperation, funded by the Norwegian Ministry for Foreign Affairs. JD's contribution to this study was supported by internal BRGM research funds. The data acquired from the Department of Earthquake Engineering, IIT Roorkee and from the Iran Strong Motion Network (http://www.bhrc.ac.ir/ISMN/Index.htm) is gratefully acknowledged. Dr. Ashok Kumar, Dr. S. Baruah and Dr. J. Das helped in compiling data for individual earthquakes. We thank Bob Engdahl for providing HDF formatted relocations for both Iranian and Himalayan earthquakes used in this study. Also, we thank Daniela Kuehn for drawing Figures 3 and 4, and we thank an anonymous reviewer for a careful review of a previous version of this article.

\section{References}

Abrahamson, N. A. and Litehiser, J. J. [1989] “Attenuation of vertical peak accelerations, ” Bulletin of the Seismological Society of America 79, 549-580.

Aitchison, J., Ali, J. R. and Davis, A.M. [2007] "When and where did India and Asia collide?," Journal of Geophysical Research, 112, B05423, doi:10.1029/2006JB004706.

Ambraseys, N. N. and Bommer, J. J. [1991] "The attenuation of ground accelerations in Europe," Earthquake Engineering and Structural Dynamics 20(12), 1179-1202.

Ambraseys, N. N., Simpson, K. A., and Bommer, J. J. [1996] "Prediction of horizontal response spectra in Europe," Earthquake Engineering and Structural Dynamics, 25(4), 371-400.

Ambraseys, N. N., Douglas, J., Sarma, S. K. and Smit, P. M. [2005] "Equations for the estimation of strong ground motions from shallow crustal earthquakes using data from Europe and the Middle East: Horizontal peak ground acceleration and spectral acceleration," Bulletin of Earthquake Engineering 3(1), 1-53.

Avouac, J. and Tapponnier, P. [1993] "Kinematic model of active deformation in central Asia," Geophysical Research Letters 20, 895-898.

Berberian, M. and King, G. [1981] "Towards paleogeography and tectonic evolution of Iran," Canadian Journal of Earth Science 18, 210-265.

Berge-Thierry, C., Cotton, F., Scotti, O., Griot-Pommera, D.-A., and Fukushima, Y. [2003]. "New empirical response spectral attenuation laws for moderate European earthquakes, "Journal of Earthquake Engineering, 7(2), 193-222.

Besse, J. and Courtillot, V. [1988] "Palaeogeographic maps of the continents bordering the Indian Ocean since the Early Jurassic." Journal of Geophysical Research B 93, 1791-1808.

Bilham R, Larson L, and Jeffrey, F. [1997] "GPS measurements of present day convergence across the Nepal Himalaya," Nature 386, 61-64.

Chiaruttini, C. and Siro, L. [1981] "The correlation of peak ground horizontal acceleration with magnitude, distance, and seismic intensity for Friuli and Ancona, Italy, and the Alpide belt," Bulletin of the Seismological Society of America 71(6), 1993-2009.

Cotton, F., Scherbaum, F., Bommer, J. J. and Bungum, H. [2006] "Criteria for selecting and adjusting ground-motion models for specific target regions: Application to central Europe and rock sites", Journal of Seismology, 10(2), 137-156. 
Das, J. D., and Chandrasekaran, A. R. [1993] "Determination of epicentre and comparison of some empirical formulae with observed data of acceleration from two events in Himalaya," Journal of the Geological Society of India 41, 417-430.

Douglas, J. [2003] "Earthquake ground motion estimation using strong-motion records: A review of equations for the estimation of peak ground acceleration and response spectral ordinates," Earth-Science Reviews 61(1-2), 43-104.

Ghasemi, H., Zare, M., Fukushima, Y. and Koketsu, K. [2009] "An empirical spectral groundmotion model for Iran, "Journal of Seismology, in press.

Hessami, K. [2002] "Tectonic history and present-day deformation in the Zagros fold-thrust belt," $\mathrm{PhD}$ thesis, University of Uppsala, Sweden.

Huang, W. C., Ni, J. F., Tilmann, F., Nelson, D., Guo, J., Zhao, W., Mechie, J., Kind, R., Saul, J., Rapine, R. and Hearn, T. M. [2000] "Seismic polarization anisotropy beneath the central Tibetan Plateau," Journal of Geophysical Research 105(B12), 27979-27989.

Jackson, J. A. [2002] "Strength of the continental lithosphere: Time to abandon the jelly sandwich," GSA Today 12, 4-10.

Jackson, J, Bouchon, M, Fielding, E, Funning, G, Ghorashi, M, Hatzfeld, D, Nazari, H, Parsons, B, Priestley, K, Talebian, M, Tatar, M, Walker, R \& Wright, T. [2006] "Seismotectonic rupture process, and earthquake-hazard aspects of the 2003 December 26 Bam, Iran, earthquake.," Geophysical Journal International 166, 1270-1292.

Jain, S. K., Roshan, A. D., Arlekar, J. N., and Basu, P. C. [2000] "Empirical attenuation relationships for the Himalayan earthquakes based on Indian strong motion data, " Proceedings of the Sixth International Conference on Seismic Zonation.

Khademi, M. H. [2002] "Attenuation of peak and spectral accelerations in the Persian plateau," Proceedings of the Twelfth European Conference on Earthquake Engineering, paper no. 330.

Maggi, A., Jackson, J. A., Priestley, K. and Baker, C. [2000] "A re-assessment of focal depth distributions in southern Iran, the Tien Shan and northern India: do earthquakes really occur in the continental mantle?" Geophysical Journal International 143, 629-661.

McCaffrey, R. and Nabelek, J. [1998] "Role of oblique convergence in the active deformation of the Himalayas and southern Tibet plateau," Geology, 26, 691-694.

McKenzie, D. P. and Fairhead, D. [1997] "Estimates of the effective elastic thickness of the continental lithosphere from Bouguer and free air gravity anomalies" Journal of Geophysical Research 102, 27523-27552.

Ni, J. and Barazangi, M. [1986] "Seismotectonic of the Zagros Continental Collision Zone and a Comparison with the Himalayas" Journal of Geophysical Research 91, 8205-8218.

Peltzer, G. and Saucier, F. [1996] "Present day kinematics of Asia derived from geological fault rates," Journal of Geophysical Research, 101, 27943-27956.

Raghu Kanth S. T. G. and Iyengar, R. N. [2007] "Estimation of seismic spectral acceleration in Peninsular India, "Journal of Earth System Sciences 116(3), 199-214.

Ramazi, H. R. and Schenk, V. [1994] "Preliminary results obtained from strong ground motion analyses of Iranian earthquakes," Proceedings, XXIV General Assembly of the ESC, III, 17621770 .

Rowley, D. B. and Currier, B. S. [2006] "Palaeo-altimetry of the late Eocene to Miocene Lunpola basin, Central Tibet," Nature, 439, 677-681.

Saini, S., Sharma, M. L. and Mukhopadhyay, S. [2002]. "Strong ground motion empirical attenuation relationship for seismic hazard estimation in Himalaya region," 12th Symposium on Earthquake Engineering, Roorkee, Dec. 16-18, Vol I, 143-150.

Sella, G. F., Dixon, T. H. and Mao, A. [2002] "REVEL: A model for recent plate velocities from space geodesy," Journal of Geophysical Research 107, 10.1029/2000JB000033.

Sharma, M. L. [1998] "Attenuation relationship for estimation of peak ground horizontal acceleration using data from strong-motion arrays in India," Bulletin of the Seismological Society of America 88(4), 1063-1069. 
Sharma, M. L. [2000] "Attenuation relationship for estimation of peak ground vertical acceleration using data from strong motion arrays in India", Proceedings, Twelfth World Conference on Earthquake Engineering, Paper no 1964.

Sharma, M. L. and P. N. Agarwal [1994] "A comparative study of few attenuation relationships," Proceedings, 10th Symposium on Earthquake Engineering, Roorkee, India, 169-176.

Sharma, M. and Bungum, H. [2006] "New strong ground-motion spectral acceleration relations for the Himalayan region," Proceedings, First European Conference on Earthquake Engineering and Seismology (ECEES), Paper 1312, 8 pp.

Shoja-Taheri, J., Naserieh, S. and Ghafoorian-Nasab, A. H. [2005] "The 2003 Bam, Iran, Earthquake: An Interpretation of the Strong Motion Records," Earthquake Spectra, 21(S1), S181-S206.

Singh, R. P., Aman, A. and Prasad, Y. J. J. [1996] "Attenuation relations for strong seismic ground motion in Himalyan region", Pure and Applied Geophysics, 147(1), 161-180.

Snyder, D. B. and Barazangi, M. [1986] "Deep crustal structure and flexure of the Arabian plate beneath the Zagros from Gravity observations," Tectonics 5, 361-373.

Tatar, M., [2001]. "Etude Sismotectonique de deux zones de collision continentale: le Zagros central et 1'Alborz (Iran)," PhD thesis, University of Joseph Fourier, Grenoble 1 France, 204 pp.

Shrikhande, M. [2001], "Strong Motion Atlas of India," Department of Earthquake Engineering, IIT Roorkee, India.

Talebian, M. and Jackson, J. [2004] "A reappraisal of earthquake focal mechanisms and active shortening in the Zagros mountains in Iran," Geophysics Journal International, 156, 506-526.

Tavakoli, B. and Ghafory-Ashtiany, M. [1999] "Seismic hazard assessment of Iran", Annali Di Geofisica, 42, The Global Seismic Hazard Assessment Program (GSHAP) 19992-1999, 10131021.

Yeats, R.S., Sieh, K. and Allen, C.R. [1997]. "The Geology of Earthquakes," Oxford University Press, New York, 568 pp.

Zafarani, H, Mousaviz, M., Noorzad, A. and Ansari, A. [2008] "Calibration of the specific barrier model to Iranian plateau earthquakes and development of physically based attenuation relationships for Iran,” Soil Dynamics and Earthquake Engineering (in press).

Zare, M., P.-Y. Bard and M. Ghafory-Ashtianya [1999a] "Site characterizations for the Iranian strong motion network," Soil Dynamics and Earthquake Engineering 18 (1999) 101-123.

Zare, M., Ghafory-Ashtiany, M. and Bard, P. Y. [1999b] "Attenuation law for the Strong Motions in Iran,” Proc., 3rd International Conference on Seismology and Earthquake Engineering, Tehran, Iran, 345-354. 